\title{
INTERACTION ORIENTATION: DO CORPORATE CULTURE, ORGANIZATIONAL STRUCTURE, AND LEADERSHIP STYLE HAVE AN IMPACT ON IT?
}

\author{
Julia Thalmann, RWTH Aachen University, Germany
}

\begin{abstract}
The term "interaction orientation" refers to the ability of firms to interact with their individual customers in such a way that the firms can gather information on products and services and can develop long-term profitable relationships. In addition, firms need customer knowledge, close customer contact, customer-based IT systems, and a focus on customer profitability in order to organize and evaluate the information they collect correctly (Day 2003). Therefore, interaction orientation actually consists of four dimensions: the belief in the customer concept, customer empowerment, interaction response capacity, and customer value management. All four dimensions aim at building close relationships with individual customers in order to gain valuable knowledge about the products and services they need and desire (Ramani and Kumar 2006). As such, interaction orientation is a firm-level strategy that ensures, through various internal activities, that the individual customer and his or her wants and needs are the objective of analysis and success (Ramani and Kumar 2008).
\end{abstract}

Other than the work of Ramani and Kumar $(2006,2008)$, scarce research on interaction orientation has been undertaken, but the literature related to firms' customer-centric thinking has called for further research on the individual customer framework (Raman et al. 2006; Shah et al. 2006). In particular, research on the organizational drivers of firms' customer-related capabilities is surprisingly scarce (Jayachandran et al. 2004). Past research on orientations, such as market orientation, has extensively examined the influence of organizational and managerial characteristics of firm-level strategies (Deshpandé and Farley 1999; Jaworski and Kohli 1993; Kirca et al. 2005), so it is important, not only for researchers but also for practitioners, to know if and how organizational and managerial antecedents affect interaction orientation.

In line with contingency theory, which views organizations as social systems in which coordination is guided through management policies to achieve goals and objectives, we examine the antecedents of interaction orientation under the organizational and behavioral contexts, as both dimensions help to adapt and coordinate an overall strategy and policy (Luthans and Stewart 1978). In order to deepen the understanding of the antecedents of interaction orientation, this study investigates the impact of firm structure, corporate culture, and leadership behavior on interaction orientation. In doing so, we examine the internal relationships and their dependencies on overall policies to broaden the understanding of operations within a firm.

The survey was conducted on executive level because the managing directors and marketing managers have best overview about the firm. As an incentive for participation in the survey, a detailed analysis of the survey results was offered. Based on a three-wave-mailing approach, 381 qualified answers were received.

The results show that both organizational and leadership characteristics either help or hinder the successful implementation of interaction orientation thereby broadening the understanding of how to implement interaction orientation successfully.

In detail, an adhocratic organizational culture is the most effective in advancing interaction orientation, while a market culture has a negative impact on it. Neither the clan culture nor the hierarchy culture has a significant influence on interaction orientation. In general, less formalized structures and highly facilitative management behavior support interaction orientation.

This study reveals that the implementation of interaction orientation alone is not sufficient to guarantee a firm's customercentric focus. The results suggest that, to foster interaction orientation on an overall firm level, managers should align organizational and behavioral factors to interaction orientation.

References available upon request. 